Please do not remove this page

RMIT

UNIVERSITY

\title{
Love mode layered surface acoustic wave filters
}

Kalantar-Zahed, Koroush; Wlodarski, W; Galatsis, Kosmas

https://researchrepository.rmit.edu.au/esploro/outputs/9921857775101341/filesAndLinks?institution=61RMIT_INST\&index=null

Kalantar-Zahed, K., Wlodarski, W., \& Galatsis, K. (2001). Love mode layered surface acoustic wave filters. Electronics Letters, 36(12), 802-803. https://doi.org/10.1049/el:20010447

Published Version: https://doi.org/10.1049/el:20010447

Repository homepage: https://researchrepository.rmit.edu.au

(c) IEE 2001. Personal use of this material is permitted. However, permission to reprint/republish this material for advertising or promotional purposes or for creating new collective works for resale or redistribution to servers or lists, or to reuse any copyrighted component of this work in other works must be obtained from the IEEE.

Downloaded On 2023/04/26 22:18:34 +1000 
$2 \mathrm{GOH}, \mathrm{Z}$, and TAN, K.: 'Kalman-filtering speech enhancement method based on a voiced-unvoiced speech model', IEEE Trans Speech Audio Process., 1999, SAP-7, pp. 510-525

3 HAYES, M.: 'Statistical digital signal processing and modeling' (John Wiley and Sons Inc., 1996), pp. 371-379

4 FURUI, S., and SONDHI, M.: "Advances in speech signal processing' (Marcel Dckker Inc., 1991), pp. 368-375

5 VORAN, S.: 'Objective estimation of perccived speech quality - Part I: development of the measuring normalizing block technique', IEEE Trans. Speech Audio Process., 1999, SAP-7, pp. 371-382

6 WANG, S., SEKEY, A., and GERSHO, A.: 'An objective measure for predicting subjective quality of speech coders', IEEE J. Sel. Areas Commun., 1992, 10, pp. 819-829

\section{Love mode layered surface acoustic wave filters}

\section{K. Kalantar-zadeh, W. Wlodarski and K. Galatsis}

Novel surface acoustic wave filters have been developed by depositing $\mathrm{SiO}_{2}$ and $\mathrm{ZnO}$ thin films onto $90^{\circ}$ rotated ST-cut quartz crystal substrates. $\mathrm{Up}$ to $19 \mathrm{~dB}$ insertion loss improvement was obtained for the filter with a $\mathrm{ZnO}$ film. The filters have no coupling with other wave propagating modes, exhibiting only one passband.

Introduction: Filters with linear-phase response are employed in communication circuits when distortion of the processed signal is to be avoided. Conventional linear phase passive L-C filters have some degree of phase nonlinearity and they are unfavourable in cost and size. By contrast, surface acoustic wave (SAW) filters with comparable performance are smaller, cheaper and have a highly linear phase response [1]. Miniaturising SAW filters is the current challenge so that they can be employed as RF bandpass filters for mobile handsets. Concerns such as low insertion loss and stability are important issues in SAW filter fabrication.

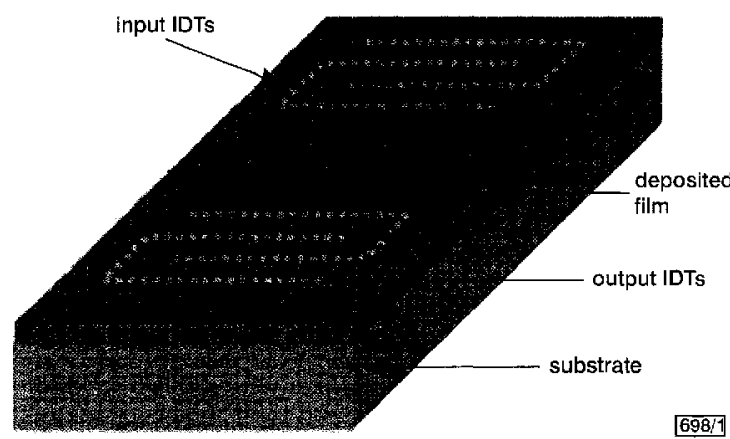

Fig. 1 Structure of layered SAW filter

Blank SAW filters have no film deposited on surface

A SAW filter generally consists of interleaved comb metal electrodes (Fig. 1) as input and output ports. In conventional structures, the inter-digital transducers (IDTs) are photo-deposited on the highly polished surface of a precisely oriented piezoelectric crystal. Signals exerted to the input port produce propagating electro-acoustic waves by means of piezoelectric coupling, which are received at the output port. The width of one IDT plus one gap between two IDTs is equal to half the wavelength of the centre frequency of the filter. With a constant wavelength, the speed of the acoustic wave propagation determines the filter centre frequency. A higher speed of acoustic wave propagation results in a higher centre frequency. Hence, to decrease the size of the filter, the speed of the acoustic wave propagation should as high as possible.

Lithium niobate and ST-cut (x-direction) quartz crystal are common materials used to fabricate SAW devices. Their main disadvantage is their low speed of acoustic wave propagation $(3800 \mathrm{~m} / \mathrm{s}$ and $3150 \mathrm{~m} / \mathrm{s}$, respectively). The low propagation speed can be improved by the deposition of piezoelectric films on non- piezoelectric high propagating speed substrates such as Si. However, in a $\mathrm{ZnO} / \mathrm{SiO}_{2}$ (for insulation)/Si [2] structure, the $\mathrm{ZnO}$ film thickness must be comparable to the wavelength. This decreases the speed of propagation to magnitudes comparable to the propagation speed of $\mathrm{ZnO}(3700 \mathrm{~m} / \mathrm{s})$. Piezoelectric films on diamond layer structures provide higher propagation speeds [3], but they are expensive and difficult to fabricate. All of the above structures have the disadvantage of coupling with other wave propagating modes, therefore as seen from Fig. $2 a$ other passbands exist.
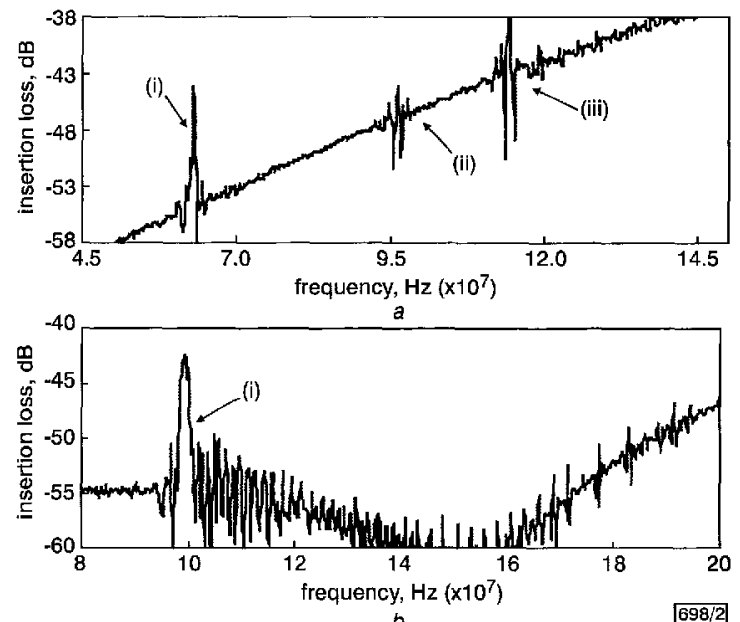

Fig. 2 Frequency response of two ST-cut quartz blank filters

a $\mathrm{x}$-direction with Rayleigh propagation mode

(i) Rayleigh wave (main harmonic)

(ii) SSBW

(iii) second harmonic

$b 90^{\circ}$ rotated with no extra coupling mode

(i) SSBW (main harmonic)

A suitable choice of substrate is $90^{\circ}$ rotated ST-cut quartz crystal since the speed of propagation is $5000 \mathrm{~m} / \mathrm{s}$ and the dominant wave is surface skimming bulk wave (SSBW). It has zero coupling to other bulk modes. It is dominantly a shear horizontal (SH) bulk wave and has a low temperature coefficient. Its major disadvantage is its high insertion loss [1]. Depositing films of different metal oxides decreases the insertion loss as it changes the mode of operation from SSBW to Love mode [4]. If the deposited film loads the substrate, the mode of propagation changes to Love mode. This occurs when the speed of SH acoustic wave propagation in the film is less than the substrate. In this Letter, $\mathrm{SiO}_{2}$ and $\mathrm{ZnO}$ films were deposited on $90^{\circ}$ rotated ST-cut quartz crystal to fabricate Love mode operating filters.

Table 1: Sputtering conditions for $\mathrm{SiO}_{2}$ and $\mathrm{ZnO}$ films

\begin{tabular}{|c|c|c|c|c|c|}
\hline Material & $\begin{array}{c}\text { Basc } \\
\text { pressure }\end{array}$ & $\begin{array}{l}\text { Sputtering } \\
\text { pressure }\end{array}$ & Power & Gas & $\begin{array}{l}\text { Deposition } \\
\text { rate }\end{array}$ \\
\hline & Torr & Torr & W & & $\mu \mathrm{m} / \mathrm{h}$ \\
\hline $\mathrm{SiO}_{2}$ & $2.5 \times 10^{-5}$ & $1.1 \times 10^{-3}$ & 140 & $90 \% \mathrm{Ar}, 10 \% \mathrm{O}_{2}$ & 0.9 \\
\hline $\mathrm{ZnO}$ & $1.5 \times 10^{-5}$ & $1.1 \times 10^{-3}$ & 60 & $60 \% \mathrm{Ar}, 40 \% \mathrm{O}_{2}$ & 0.6 \\
\hline
\end{tabular}

Configuration of filters and fabrication process: Love mode filters have been fabricated on $90^{\circ}$ rotated $0.5 \mathrm{~mm}$ thick ST-cut quartz substrates. The input and output IDTs consist of 64 and 16 IDT pairs, respectively, with $50 \mu \mathrm{m}$ periodicity and an aperture of $3 \mathrm{~mm}$. $\mathrm{SiO}_{2}$ (with the propagation speed of $2850 \mathrm{~m} / \mathrm{s}$ ) and crystallographically c-axis oriented [2] $\mathrm{ZnO}$ films were deposited using $\mathrm{RF}$ magnetron sputtering, with a thicknesses of $1.5 \mu \mathrm{m}$. The sputtering conditions are shown in Táble 1.

Results and discussions: Insertion losses were examined by measuring the transmission $S$ parameters. $S$ parameters were measured using a network analyser. The network analyser had a $50 \Omega$ line impedance. The measurements indicate that the operating mode of a $90^{\circ}$ rotated ST-cut quartz crystal filter has no extra coupling modes (Fig. 2b). Fig. 3 shows the frequency response of a blank filter together with $\mathrm{SiO}_{2}$ and $\mathrm{ZnO}$ filters on $90^{\circ}$ rotated ST-cut quartz crystal. 
The $\mathrm{ZnO} / \mathrm{ST}$-cut quartz crystal structure possesses a lower insertion loss. In this case, the insertion loss is $19 \mathrm{~dB}$ less than the blank quartz crystal filter and $6 \mathrm{~dB}$ better than the $\mathrm{SiO}_{2} / \mathrm{ST}$-cut quartz crystal structure. The acoustic signals on both layered structures are dominantly $\mathrm{SH}$, since an insignificant change in insertion loss occurs when the surface of the filter is loaded with a low-viscous liquid. Owing to the difference in magnitudes of propagation speeds in the deposited layers and substrate [4], the propagation mode of the filter is expected to be Love mode. The insertion loss is less in the layered structures as SSBWs change to Love waves where the waves are dominantly propagating near the surface and in the deposited layers. The $\mathrm{ZnO}$ based acoustic filter has a lower insertion loss compared to the blank and $\mathrm{SiO}_{2}$ based filters due to the piezoelectric nature of $\mathrm{ZnO}$, which increases the coupling coefficient of the structure.

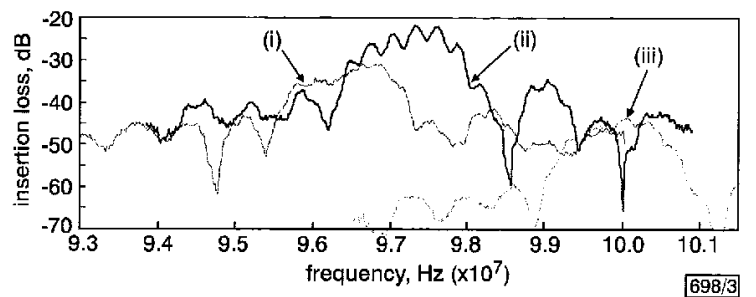

Fig. 3 Frequency response of $\mathrm{ZnO} / \mathrm{ST}$-cut quartz crystal structure, $\mathrm{SiO}_{2}$ $S T$-cut quartz crystal structure and blank filters

\section{(i) $\mathrm{SiO}_{2}$ film \\ (ii) $\mathrm{ZnO}$ film}

(iii) blank

Conclusion: Novel filters with $\mathrm{SiO}_{2} / 90^{\circ}$ rotated ST-cut quartz crystal and $\mathrm{ZnO} / 90^{\circ}$ rotated ST-cut quartz crystal structures have been fabricated. They show an improved insertion loss compared to the blank quartz crystal filters. Propagation modes show no coupling with other modes and due to their high speed of propagation, they are smaller in size.

Acknowledgments: The authors would like to thank CRC for Micro-Technology, Australia, for financial support.

\section{(C) IEE 2001}

19 April 2001

Electronics Letters Online No: 20010447

DOI: 10.1049/el:20010447

K. Kalantar-zadeh, W. Wlodarski and K. Galatsis (RMIT University, School of Electrical and Computer Systems Engineering, Victoria 3001 , Australia)

E-mail: kourosh@kalantar.org

K. Kalantar-zadeh, W. Wlodarski and K. Galatsis: Also with CRC for Micro-Technology, Hawthorn, Victoria 3122, Australia

\section{References}

1 CAMPBELL, C.K.: 'Surface acoustic wave devices for mobile and wireless communications' (Academic Press, 1998)

2 YAMAZAKI. O., MITSUYU T., and WASA, $\mathrm{K}$ : ' $\mathrm{ZnO}$ thin-film SAW devices', IEEE Trans., SU-27, (1980), pp. 369-379
3 NAKAHATA, H., HIGAKI, K., HACHIGO, A., SHIKATA, S., FUJIMORI, N., TAKAHASHI, Y., KAJIHARA, T., and YAMAMOTO. Y.: "High frequency surface acoustic wave filter using $\mathrm{ZnO} / \mathrm{Diamond} / \mathrm{Si}$ structure', Jpn. J. Appl. Phys., 1994, 33, pp. 324-328

4 OLINER, A.A.: 'Topics in applied physics: acoustic surface waves' (Springer Verlag, 1978), Vol. 24

\section{Errata}

LIZHI CHENG, HUI XI, and YoNG LUO: 'Integer discrete cosine transform and its fast algorithm', Electron. Lett., 2001, 37, (1), pp. 64 65

Author's correction

$P_{N}^{(2)}, P_{N}^{(3)}$ and $B_{N}$ should read

$$
\begin{aligned}
& P_{N}^{(2)}=\operatorname{Bdiag}\left\{I_{\frac{N}{2}}, P_{\frac{N}{2}}^{(1)}\right\} \\
& P_{N}^{(3)}=\operatorname{Bdiag}\left\{I_{\frac{N}{2}},-I_{\frac{N}{4}}, \operatorname{diag}(1,-1, \ldots, 1,-1) J_{\frac{N}{4}}\right\}
\end{aligned}
$$

and

$$
\begin{array}{r}
B_{N}=\operatorname{Bdiag}\left\{I_{\frac{N}{2}}, J_{\frac{N}{2}} * \operatorname{Bdiag}\left\{1, \frac{\sqrt{2}}{2}\left[\begin{array}{cc}
1 & 1 \\
-1 & 1
\end{array}\right],\right.\right. \\
\left.\left.\ldots, \frac{\sqrt{2}}{2}\left[\begin{array}{cc}
1 & 1 \\
-1 & 1
\end{array}\right], 1\right\}\right\}
\end{array}
$$

STEINLE, G., MEDERER, F, KICHFRER, M., MICHALZIK, R., KRISTEN, G., EGOROV. A.Y., RIECHFRT, H., WOLF, H.D., and EBELING, K.J.: 'Data transmission up to $10 \mathrm{Gbit} / \mathrm{s}$ with $1.3 \mu \mathrm{m}$ wavelength InGaAsN VCSELs', Electron. Lett., 2001, 37, (10), pp. 632-634

Editor's correction

Fig. 2 should have appeared as follows:

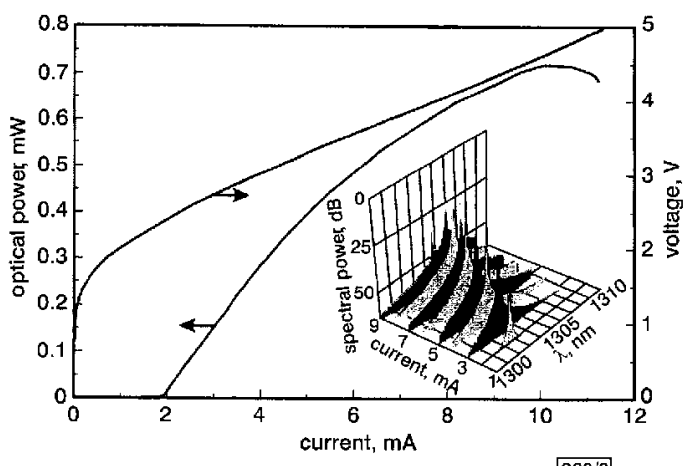

Fig. $2 \mathrm{CW}$ properties and emission spectrum at various pump currents of 3 to $9 \mathrm{~mA}$

Multimode operation is found for currents above $9 \mathrm{~mA}$ 